\title{
Lo público y lo privado en la obra de Jean-Jacques Rousseau
}

\author{
FERNANDO CALDERÓN QUINDÓS \\ Universidad de Valladolid
}

En este artículo los conceptos de público y privado son empleados como dos herramientas teóricas complementarias, válidas en la tarea de armonizar el pensamiento político y moral de Jean-Jacques Rousseau. El propósito es doble: reconocer en el espíritu del concepto de «soberanía popular» el maridaje entre las esferas pública y privada, sin subordinación de ésta a aquélla; y advertir asimismo la necesidad de subordinar cualquiera de las dos a la otra cuando el tiempo, el lugar y las circunstancias así parezcan recomendarlo.

\section{Introducción}

La obra de Jean-Jacques Rousseau ha sido muchas veces mal entendida, y no pocas veces mal intencionadamente. Sin embargo, creo que hay un modo bastante seguro de hacerle justicia, y que si bien nunca podrá preservarnos de nuestra torpeza, al menos podrá garantizarnos contra acusaciones peores. El método no exige adoptar demasiadas precauciones, y su aplicación es tanto más pertinente y fiable cuanto que es Rousseau quien nos lo propone: «Todas mis ideas son coherentes, pero no me es posible exponerlas a la vez» 1 ; «advierto al lector (...) que no poseo el arte de ser claro para quien no quiere prestar atención» ${ }^{2}$, y «pido la gracia de que se me conceda el tiempo de explicarme» ${ }^{3}$. Puesto que me sería imposible adoptar a pies juntillas estas advertencias sin tener que renunciar a la tarea de seguir escribiendo, las respetaré en tanto que pueda y cederé el lugar de mis explicaciones a las suyas toda vez que no sepa explicarme tan claramente como él.

En el mes de agosto de 1762 Christophe de Beaumont, Arzobispo de París y Par de Francia, publicó un mandamiento contra el Emilio. Rousseau se vio en la obligación de defenderse de falsas acusaciones dirigidas contra su persona, ocasión que aprovechó para demostrar su malestar con respecto a bastantes de sus lectores. «Se han formulado juicios contrapuestos sobre mis libros, porque se me ha juzgado por las materias de que he tratado mucho más que por mis convicciones (...). Así va fluctuando el necio público a mi respecto, tan sin saber por qué me odia como por qué antes me apreciaba» ${ }^{4}$. Si bien es cierto que estos reproches no constituían ninguna salida de tono, también lo es que a Rousseau no podían sorprenderle muchos de los equívocos a que su obra daba lugar. Su gusto natural por la paradoja resultaba a la vez provocador y desconcertante, y su costumbre de mantener el uso de los términos en una constante agitación semántica desafiaba cualquier convención ${ }^{5}$. No es raro, en fin, que de la conjunción de estas dos aficiones se originasen malentendidos entre sus lectores; Rousseau no tardó en darse cuenta de ello, pero la suerte estaba echada y ya no le cabía otra esperanza que la de encomendarse al juicio de la posteridad. Sin embargo, durante sus años postrimeros sintió vivamente el temor de no ser nunca comprendido o, dicho de modo más exacto, de caer una y otra vez «en manos de los estamentos que me han tomado aversión» 6 .

El 14 de febrero de 1776, cercana ya su muerte, casi toda esperanza agotada, 
Rousseau quiso ampararse en la única que todavía creía tener: la divina Providencia. Pero esa mañana de invierno el coro de la Catedral de Notre-Dame apareció enrejado y Rousseau, que pretendía depositar sus Diálogos en el altar mayor, tuvo que renunciar a hacerlo. Después de los Diálogos vinieron las Ensoñaciones. Cansado de batallar, harto de prestar su persona a las chanzas de sus contemporáneos, viejo y enfermo como estaba, la tarea de pensar en la sociedad de los hombres se le hacía ya demasiado fatigosa. Después de una vida consagrada a una humanidad ingrata, Rousseau decidía ahora entregarse en cuerpo y alma al cuidado de sí mismo, al sentimiento maravilloso de su propia existencia, y a largos y solitarios paseos entre los inocentes encantos de la naturaleza. Quince años después de la publicación de El Contrato Social, Rousseau seguía siendo el mismo. Sin embargo, las circunstancias habían experimentado un cambio sorprendente y Rousseau, ciudadano de Ginebra ${ }^{7}$ en otro tiempo, será ahora, más aún que en aquellos meses de Montmorency, un oso ermitaño ${ }^{8}$ contento por fin de abrazar su independencia.

El corazón de Rousseau siempre estuvo disputado por dos sentimientos contrapuestos: uno le inspiraba un gusto irreformable por la independencia y el retiro; el otro le interesaba por la suerte de los hombres, por la conservación de éstos y por la libertad y felicidad de los pueblos. Ambos sentimientos aguijoneaban su corazón sin cesar: aquél le trasladaba a «una hermosa orilla» ${ }^{9}$ en la que el hombre vivía tranquilo, solo y autosuficiente acogido en el seno de una naturaleza benefactora; este otro, más ingrato sin duda, le devolvía al drama de los hombres reunidos, al incierto porvenir de las naciones y a sus más tristes y dolorosos desvelos. Los hombres habían renunciado a su libertad a cambio de una existencia tranquila, y este trueque, al que todos los hombres parecían haber asentido de buena gana, desgarraba brutalmente el corazón de Rousseau. «Renunciar a la libertad es renunciar a la cualidad de hombre, a los derechos de la humanidad y aun a sus deberes» ${ }^{10}$; si todavía nos es querida nuestra naturaleza, restituyamos la libertad que abandonamos en los bosques, dotemos a nuestras acciones de la moralidad que les es debida, y convirtámonos en virtuosos ciudadanos sin despreciar el bello honor de haber nacido hombres. Mas si ya no podemos ser libres por nuestra cuenta y riesgo, ¿cómo podremos volver a serlo?: apelando a la sagrada convención del pacto, de modo tal que siendo para todos mucho menos gravoso que útil, no quiera nadie sustraerse de aquél sin renunciar asimismo al ejercicio del más precioso de todos nuestros derechos: el de la libertad.

\section{Genealogía de lo público y de lo privado}

El Contrato Social no es ninguna «Utopía». Rousseau se tomó la molestia de decirlo, pero su advertencia apenas fue considerada. El Contrato Social es, si se quiere, el compromiso con una idea irrealizable, pero el valor de esta idea — quede esto muy claro- no depende de sus posibilidades de ejecución. El Contrato Social es una propuesta de solución demasiado encumbrada como para alcanzar a rozarla alguna vez, pero el empeño de acercárnosla no es en balde, porque su presencia alienta nuestra libertad moribunda y compromete a cada ciudadano con todos los demás. Se trata, en definitiva, de un ejercicio teórico deliberadamente desprendido de cualquier concreción ${ }^{11}$ porque «creo que sólo puede haber evidencia en las leyes naturales y políticas consideradas en abstracto» ${ }^{12}$. Una vez establecida esta evidencia, podremos pensar cabalmente en otorgar a cada uno de los pueblos dispersos por la Tierra la clase de gobierno que más les convenga. Es, por cierto, la imposibilidad de poner en práctica las demandas 
contractuales propuestas por Rousseau, lo que demuestra que en las cosas de los hombres todo es susceptible de más y de menos así sean unas $u$ otras las circunstancias.

Entremos por fin en materia formulándonos esta pregunta iqué ocurre con lo público y lo privado?: respondamos con lo que las circunstancias dispongan. Hagamos la pregunta de otro modo: ¿Hay alguna circunstancia que por ser común a todos los pueblos incline nuestra elección más de un lado que de otro, y cuyo vigor y resistencia sean tales que podamos garantizar nuestra elección sin el temor de habernos equivocado?: esta circunstancia existe, pues los hombres, además de hombres, son desde hace mucho ciudadanos. Imagínese una sociedad de hombres tramposos, malvados y ladrones entre quienes el asesinato, la calumnia y el fraude se devuelven con casi toda impunidad; me cuesta imaginar qué ventajas podrían tener, qué beneficio común obtendrían esos hombres de su convivencia, qué cosa atraería sus vidas a lo público importándoles tan sólo ese feroz interés, pero debe de haber ventajas a pesar de que yo las ignore, pues, ¿por qué razón si no habrían de mantenerse unidos? Imagínese ahora una sociedad de hombres sin la temible ferocidad de aquéllos, pero con pasiones semejantes a las nuestras; uno se acerca a nosotros y nos dice que «lo público me importa un comino con tal de que nadie meta sus narices en mis asuntos», pero este hombre no sabe lo que dice y mucho menos lo que le interesa, porque la suerte de sus negocios parece depender bastante de los designios de la voluntad pública. Imagínese, por último, una sociedad de Numas, Fabricios y Catones, una sociedad de ciudadanos virtuosos dedicados en cuerpo y alma a las tareas públicas, sin tiempo para nada más y con sus mujeres siempre atentas a las labores del hogar; lo privado ocuparía en el corazón de estos hombres un lugar puramente testimonial, y quién sabe si por mor del bien público no estarían también dispuestos a sacrificar esta exigua porción.
Genealógicamente lo privado precede a lo público, pero una vez instituidas las sociedades, lo público precederá siempre a lo privado. Aquella relación depende del orden de la naturaleza por cuanto tiene su origen en un estadio inmediatamente anterior al del ingreso del hombre en sociedad; esta otra relación, en cambio, depende de la política, pues hay que buscar su origen allí donde nace la historia de los hombres reunidos. Es fácil proponer la siguiente objeción a esta clase de relaciones: icómo sostener que lo privado fue genealógicamente anterior a lo público cuando, antes de devenir ciudadanos, fuimos salvajes solitarios sin idea alguna de lo «tuyo»y de lo «mío»? Mucho más sensato sería pensar en una comunidad de salvajes ${ }^{13}$ repartidos por todos los climas y continentes, en la que «los frutos son de todos y la Tierra no es de nadie» ${ }^{14}$. Sin embargo, no debe olvidarse que después de que los hombres fueran salvajes y antes de que llegasen a formar sociedad hubo, según Rousseau, un instante intermedio en la historia de la humanidad en el que «los primeros progresos del corazón fueron efecto de una situación nueva que reunía en una habitación común a maridos y mujeres, a padres e hijos (...). Cada familia vino a ser una pequeña sociedad ${ }^{15}$. Pero concluir que lo público tiene su ascendiente sobre lo privado es, hasta este punto, apercibirse de una simple cuestión de hecho. Se trata de un presupuesto irrenunciable, de una condición sine qua non, y casi podría decirse que de un asunto meramente formal si no fuera porque el interés por conservarse es común a todo hombre sin excepción.

\section{Lo público y lo privado, sometidos a la violencia de las circunstancias}

Olvidemos la comunidad de la naturaleza y volvamos nuestra mirada al Siglo de las Luces; volvamos de esas «selvas inmensas que jamás mutiló el hacha» ${ }^{16}$, a las «rien- 
tes campiñas» ${ }^{17}$ en que las hemos convertido, y en que vemos a la «miseria germinar y crecer con las mieses» ${ }^{18}$. El espectáculo de los pueblos modernos es, para Rousseau, el triste homenaje que el hombre rinde a Quien le puso en disposición de hacer uso de su libertad, y, su Contrato Social, el texto en el que se contiene una seria propuesta de reforma. Sin embargo, Rousseau no escribió este libro para que se lo entendiese al pie de la letra, y menos aún para que los pueblos, muy distintos entre sí, otorgaran a ese breviario político toda la fuerza de la acción. Cualquiera que lea esta obra podrá advertir fácilmente que la utilidad común por la que los hombres se unen exige un compromiso recíproco irrenunciable, pues todo pueblo debe ser soberano, y la soberanía es indivisible e inalienable; sin embargo, debe recordarse que sólo puede haber evidencia en las leyes naturales y políticas consideradas en abstracto, y que una vez desprendidas de este molde, «la ciencia de gobernar no es sino una ciencia de combinaciones, aplicaciones y excepciones, según el tiempo, lugar y circunstancias» ${ }^{19}$. Lo público y lo privado serán dos variables expuestas a un trasiego constante cuya determinación exige ponderar escrupulosamente el juego de las circunstancias.

Pero puesto que El Contrato Social no nos dice en ningún caso lo que debemos hacer, sino lo que tendríamos que haber hecho, empecemos por considerar este punto para caer luego en la cuenta de lo que cada pueblo está todavía en condiciones de hacer para su propio beneficio. El soberano, que no admite representación, es el encargado de proponer, discutir e instituir las leyes. El soberano es enteramente libre de promulgar la ley que sea, y si es de su voluntad disolverse, nadie podrá arrogarse el derecho de impedírselo. Imagínese que un período prolongado de bonanza económica pone a la mayoría de los súbditos del Estado en situación de vivir holgadamente sin depender de sus vecinos, circunstancia que unida a otras convence al legislador para redactar una ley que exima a sus conciudadanos de la tarea de concurrir a los actos de deliberación pública. La aprobación de esta ley se convertiría en el último acto soberano después del cual los ciudadanos dejarían de serlo irremisiblemente. En otras palabras: cuando la atención a los asuntos privados pone al súbdito en situación de descuidar las tareas públicas, entonces el pacto se rompe y el ciudadano se despoja de sus deberes y derechos para mantener sólo los que le quedan como hombre.

Por otro lado, debe advertirse, no obstante, que el valor de lo privado no es despreciado por Rousseau y no sólo porque, tocante a la propiedad, esté de acuerdo en que cada uno conserve la suya según determinadas proporciones. El legislador debe «persuadir sin convencer» ${ }^{20}$, nos dice Rousseau, advertencia que no sólo nos informa de la clase de discurso que el legislador debe pronunciar, sino también de la clase de instrucción que todo ciudadano debe tener. El legislador, propietario de una inteligencia superior, dirige al auditorio hacia la opinión que el mismo tiene, pero no le determina en ésta. Su voluntad no persigue disolver la de cada ciudadano en la suya, sino comparar las razones que determinan la de cada uno con las suyas propias. Apenas iniciado $\mathrm{El}$ Contrato Social, Rousseau confiesa: «Nací ciudadano en un Estado libre y, miembro del soberano, por muy débil influencia que pueda tener mi voz en los asuntos públicos, me basta el derecho a votar sobre los mismos para imponerme el deber de instruirme a su respecto» ${ }^{21}$. Todo ciudadano debe tener y dar su propia opinión sobre cualquier asunto público, dado que las opiniones de partido ejercen invariablemente un efecto pernicioso sobre la voluntad general. Las asociaciones parciales son voluntades intermedias capaces de malograr los resultados de la deliberación pública, pues bien podría darse la circunstancia de que 
un partido contase con tantos afiliados que su interés terminase prevaleciendo sobre toda la comunidad.

Hay, por último, un detalle que ha pasado comúnmente desapercibido, al menos hasta donde yo sé, y sobre el que me parece pertinente detenerse. Ya dijimos que ninguna instancia puede pedirle cuentas al soberano. Éste es un cuerpo absolutamente libre cuya única traba no puede decirse seriamente que lo sea, pues advertir que es absurdo que la voluntad se ponga cadenas para el futuro es tanto como instarnos a tomar medidas contra lo que de ningún modo tendríamos la ocurrencia de hacer: condenar explícitamente nuestra libertad por obra de nuestra propia libertad. Sin embargo, el rigor con que El Contrato Social define el concepto de soberano parece relajarse sensiblemente en lo tocante a «las personas privadas que lo componen» ${ }^{22}$, es decir, cuando la convención del pacto y la voz de la naturaleza entran en la disputa de sus derechos. Por un lado, el soberano puede hacer uso de su libertad a discreción, y si es de su voluntad «hacerse mal a sí mismo» ${ }^{23}$ se lo hará de todos modos; por otro lado, los súbditos conservan la dignidad de haber nacido hombres, y aunque se deben al Estado en que han nacido o por aquel por el que fueron adoptados, «su vida y libertad son naturalmente independientes» ${ }^{24}$ del soberano, por lo que éste «no puede cargar a los súbditos con ninguna cadena inútil para la comunidad» ${ }^{25}$. Pero si el soberano es libre de provocarse daño, ¿no es meterse en sus asuntos querer impedírselo?: parece que sí. ¿No es asimismo inimaginable que el soberano quiera hacer inútilmente gravosa la vida de sus súbditos?: sin duda que lo es. Luego es ridículo temer que alguna vez pueda ocurrir. En la parte que el súbdito conserva sólo para sí, ningún interés ajeno podrá venir a estorbarle impunemente. El disfrute de la vida privada, en consecuencia, está amparado en el espíritu de la voluntad general, porque encadenar inútilmente al súbdito al desempeño de obligaciones absurdas repudia a esa voluntad que ues siempre recta y que tiende siempre a la utilidad pública» ${ }^{26}$.

Todo esto está muy bien, pero ni hubo ni habrá nación de la que podamos extraer todas estas sabias lecciones. Hay numerosas circunstancias sin las cuales es imposible devolver a los pueblos a su libertad, y sería un prodigio que todas ellas se diesen a la vez en una región circunscrita. Por tanto, sólo puede confiarse en el éxito de un óptimo relativo según la suerte de las condiciones iniciales, de lo que se sigue que cada pueblo tendrá un límite más abajo del cual no pueda caer y otro más arriba del cual le sea imposible encumbrarse. La suerte de lo público y de lo privado dependerá en cada caso del número y valor de las circunstancias. De todo esto se sigue que debe renunciarse a la tarea de comparar el estado de los pueblos con respecto al de cada uno, porque lo que conviene a un pueblo puede no convenir a su vecino. Neuchâtel o cualquiera de los cantones de Suiza ¿podrán compararse con las poblaciones amerindias?; ¿qué tienen que ver los antiguos suizos, entre quienes «los ríos y torrentes que los separaban proporcionaban a cada uno los medios para prescindir de sus vecinos» ${ }^{27}$, con Francia o Inglaterra?; ¿qué habrá de común entre esos «gobiernos tan sabiamente ponderados, caídos en la decrepitud» ${ }^{28}$, con Polonia, «esta región despoblada, devastada, oprimida, abierta a sus agresores, en el máximo de sus desgracias y de su anarquía» ${ }^{29}$ ? Probablemente hombres con muchos vicios y casi ninguna virtud, amantes sin excepción de la libertad y esclavos casi todos.

Algunas naciones ocupan tan anchas geografías que parece incluso inverosímil que los hombres que las habitan puedan vivir bajo el mismo gobierno. Las estaciones, los climas, la fertilidad de los suelos, la proximidad del mar, cualquier circunstancia tiene su consecuencia sobre los 
hombres, y si se quiere que los ciudadanos todavía compartan lo bastante como para seguir considerándose miembros de aquél, hará falta reanimar en el corazón de aquéllos el sentimiento patrio que nunca deberían haber perdido. Las costumbres, esa cuarta categoría de leyes contemplada por Rousseau en El Contrato Social, adquieren en la inmensidad de estas naciones una importancia inapreciable. La uniformidad de las costumbres y el apego de cada uno a todas ellas tendrían que ser tales que, por decirlo así, las estaciones, los climas y los suelos se arrimasen desde todas partes hasta aglutinarse, mezclarse y acabar finalmente confundiéndose. Polonia es el ejemplo que Rousseau propone. Se trata de un país de dimensiones desproporcionadas, amenazado por sus divisiones internas tanto como por las potencias vecinas, miserable y débil aunque amante de su libertad y de sus leyes. Si Polonia quiere recuperar el vigor de otro tiempo, ¿de qué medios habrá de valerse? «¿Osaré decirlo? Mediante juegos de niños» ${ }^{30}$ siempre públicos de modo que éstos se acostumbren tempranamente «a la regla, a la igualdad, a la fraternidad, a la emulación, a vivir bajo la mirada de sus conciudadanos y a desear la aprobación pública» ${ }^{31}$. Estas medidas, de las que seguramente bien podrían prescindir otros pueblos, exigen el sacrificio a lo público de lo privado, y responden a circunstancias excepcionales alejadas del círculo perfecto de las evidencias políticas.

Pueblos como el polaco necesitan a todos los hombres en el interior de sus fronteras, porque al temor cierto de ser invadido no puede oponérsele seriamente la fuerza de la ley, sino la de los brazos, pues sólo con los brazos se empuñan el arma y los aperos del campo. Pero en un pueblo en que la defensa está suficientemente cubierta y las pasiones desbocadas, el servicio que el buen ciudadano tiene el deber de prestar se ejercitará con mayor aptitud en tierra extraña o en cualquier punto en que el espíritu pueda recobrar su serenidad y la vigilancia de sus pasiones. «Algo es, cuando se carece de fuerza y salud para trabajar con las manos, osar desde el retiro hacer oír la voz de la verdad. Algo es advertir a los hombres de la locura de las opiniones que los hace miserables» ${ }^{32}$. He aquí otra circunstancia por la que un hombre, el propio Rousseau, tuvo que renunciar al trato diario de sus vecinos para trabajar por el bien de Ginebra, su pueblo. Esta excepción tampoco podría haber sido nunca contemplada en $\mathrm{El} \mathrm{Con}$ trato Social.

\section{Lo público, lo privado y la mujer como excepción}

La vasta región del mundo alberga hombres de toda clase y condición repartidos entre pueblos no menos distintos entre sí. Unos conservan el brío de la juventud y son aguerridos, otros son feroces e ignorantes, algunos son sabios y sin escrúpulos, los hay sanguinarios y enemigos del mundo entero, los hay pacíficos y serviles, unos pocos empeñan su vida en la libertad, y todavía menos son los hombres y pueblos que nacen, viven y mueren habiendo sido siempre libres. Ante esta miscelánea de hombres, en el fondo iguales, la aspiración de proponer reformas universales y absolutas parece escasamente recomendable. Las reformas deberán ser siempre relativas, pues aunque los hombres son naturalmente libres e iguales, no puede suponerse que los ciudadanos lo sigan siendo en esa misma armónica proporción. Ahora bien, iesta versatilidad de las cosas del hombre debe aplicarse indiscriminadamente? O de otro modo, ¿hay algún colectivo, sociedad o agrupación que deba ser exceptuado de ser tratado según la circunstancia? Rousseau no parece tener ningún reparo en hacer de las mujeres esa excepción. 
Rousseau fue un adalid de la libertad: los padres del derecho natural aseguraban que fue el entendimiento lo que distinguió a los hombres de las primeras bestias; Rousseau depondrá el entendimiento para coronar al hombre con su condición de agente libre. Frente a las rancias monarquías de Europa, proclamaba la soberanía de todos los pueblos; al materialismo desgarrador de sus contemporáneos, opuso la evidencia del espíritu; contra la educación impartida por las órdenes religiosas, demasiado interesadas en perpetuar los cuadros del Antiguo Régimen, quiso Rousseau formar ciudadanos capaces de pensamiento crítico... Pero, ipor qué entonces no quiso conceder a las mujeres la misma libertad que se afanó tanto en querer devolver a los hombres?, es decir, ¿por qué impuso a la mujer su dedicación irrenunciable al ámbito doméstico?

Los hombres han nacido todos libres e iguales, y en esa libertad e igualdad se funda el derecho natural. Sin embargo, hubo un episodio en la historia de la humanidad, ese mismo en que cada familia vino a formar una pequeña sociedad, que inclinó la balanza de los sexos del lado del varón. «Las mujeres se hicieron más sedentarias y se acostumbraron a guardar la choza y los hijos mientras que el hombre iba en busca de la subsistencia común» ${ }^{33}$. Este episodio aconteció tardíamente, y el feminismo interesado en Rousseau lo sitúa entre el estado de pura naturaleza y el estado social. Para autoras como Rosa Cobo o Carol Pateman, Rousseau se habría amparado en la peculiaridad de este episodio intermedio con el propósito de justificar la subordinación de la mujer.

La descripción del estado de naturaleza propuesta por Rousseau contenía una clara intención política: recuperar para los ciudadanos la libertad e igualdad que todos ellos, en tanto que despojados injustamente de una y otra, se encuentran en el derecho de reclamar. Todos ellos excepto la mujer, quien antes de que hiciera su ingre- so en la sociedad civil, puso su vida en manos de su pareja. Cuando las familias decidieron unirse para vivir en sociedad la mujer fue restituida en su estado o, de otro modo, se le restauró en la sociedad civil la subordinación a la que ya estaba siendo obligada en el estado de naturaleza. El hombre, en cambio, perdió la libertad con la que había nacido, y aunque siguió manteniendo su ascendiente sobre su pareja, salió perdiendo en todo lo demás. El hombre que quiere ser libre en sociedad, nos avisa Rousseau, sólo podrá serlo como miembro del soberano, es decir, consagrando su vida a la actividad pública, demasiado fatigosa para ocuparse de nada más y demasiado importante como para compaginarla con las tareas en las que las mujeres se desenvuelven tan bien.

La diferencia entre la esfera pública y la esfera privada depende tanto de la naturaleza de los asuntos como de la naturaleza de los sexos. Si el hombre pudiese desatender sus obligaciones con lo público, éste podría llegar a un acuerdo con su mujer para dividirse las tareas del hogar, pues se trata de un ámbito discreto y, para decirlo burdamente, mientras el marido barre el porche la mujer puede ir oreando la ropa al sol. Pero si la mujer pudiera deshacerse de sus tareas culinarias, su actividad pública no podría ser en ningún caso, porque la virtud consiste en «la conformidad de la voluntad particular con la voluntad general» ${ }^{34}$, y la mujer no sabría tener otra que la suya. Más allá de la vida doméstica, donde la piedad y la ternura apenas valen nada, la mujer tampoco valdrá nada. La piedad es un sentimiento que depende de la proximidad del objeto que lo inspira; quien sólo puede sentir piedad jamás podrá ser justo, y en cualquier acto en que se exija justicia jamás podrá invocarse la voz de una mujer. Es la piedad la virtud que sirve al ginebrino para ridiculizar cualquier demanda de participación política femenina, y es, en cambio, la justicia la virtud que promueve la acti- 
vidad pública del varón. «Cuanta menos inmediata relación con nosotros mismos tiene el objeto de nuestro afán, menos temible es la ilusión del interés particular, cuanto más se generaliza este interés, más equitativo se hace, y el amor del linaje humano no es otra cosa en nosotros que el amor a la justicia» ${ }^{35}$.

\section{BIBLIOGRAFÍA}

Obras de J. J. Rousseau empleadas en el trabajo:

Cartas a Sofía, Madrid, Alianza Editorial, 1999.

«Carta a Mirabeau», en Escritos polémicos, Madrid, Tecnos, 1994.

«Cartas a Malesherbes», en Escritos polémicos, Madrid, Tecnos, 1994.

«Carta a d'Alembert», en Escritos de combate, Madrid, Alfaguara, 1979.

«Carta a Christophe de Beaumont», en Escritos de combate, Madrid, Alfaguara, 1979.

«Discurso sobre las Ciencias y las Artes», en Escritos de combate, Madrid, Alfaguara, 1979.
«Discurso sobre el Origen y los Fundamentos de la Desigualdad entre los Hombres», en Escritos de combate, Madrid, Alfaguara, 1979.

«El Contrato Social», en Escritos de combate, Madrid, Alfaguara, 1979.

Emilio, Barcelona, Fontanella, 1973.

Las ensoñaciones del paseante solitario, Madrid, Cátedra, 1986.

Proyecto de Constitución para Córcega. Consideraciones sobre el Gobierno de Polonia y su proyecto de reforma, Madrid, Tecnos, 1988.

\section{Bibliografía secundaria}

CAssirer, E., The Question of Jean-Jacques Rousseau, 2. ${ }^{\text {a }}$ ed., Yale University Press, London, 1989.

Rosenblatt, H., Rousseau and Geneva, Cambridge University Press, Cambridge, 1997.

Peña Echeverría, J., «Rousseau y la idea de comunidad política», Isegoría, Madrid, 11, 1995.

\section{NOTAS}

1 J.-J. Rousseau, «El contrato social», en Escritos de combate, Madrid, Alfaguara, 1979, p. 430.

${ }^{2}$ Ibidem, p. 451

3 J.-J. Rousseau, «Consideraciones sobre el Gobierno de Polonia», en Proyecto de Constitución para Córcega. Consideraciones sobre el Gobierno de Polonia y su Proyecto de Reforma, Madrid, Tecnos, 1988, p. 144.

${ }^{4}$ J.-J. Rousseau, «Carta a Christophe de Beaumont», en Escritos de combate, pp. 522-523.

${ }^{5}$ En palabras de E. Cassirer, Rousseau «opposed the essentially static mode of thought, feeling and passion. His dynamics still holds us enthralled today» (E. Cassirer, The Question of Jean Jacques Rousseau, Londres, New Haven and London, 1989, p. 36.

${ }_{6}^{6}$ J.-J. Rousseau, Las ensoñaciones del paseante solitario, Madrid, Cátedra, 1986, p. 47.

${ }^{7}$ Rousseau renunciará en 1763 al estado de vecino de Ginebra.
8 Así solía llamarlo su protectora y amiga Madame d'Epinay durante la estancia de éste en l'Ermitage.

9 J.-J. Rousseau, «Discurso sobre las ciencias y las artes», en Escritos de combate, p. 23.

${ }_{10}$ J.-J. Rousseau, El contrato social, p. 406.

${ }^{11} \mathrm{H}$. Rosenblatt rechaza en su libro (Rousseau and Geneva, Cambridge University Press, 1997) cualquier interpretación utópica, pero comete un considerable error al adoptar un punto de vista demasiado específico que condena la universalidad de Du Contrat Social. Quizá la república de Ginebra necesitaba ser refundada, pero Rousseau no escribió este libro para lectura exclusiva de sus conciudadanos, sino para toda la humanidad.

12 J.-J. Rousseau, «Carta al marqués de Mirabeau», en Escritos de combate, p. 269.

${ }_{13}$ El profesor de la Universidad de Valladolid, Don Javier Peña Echeverría, en su artículo «Rousseau y la idea de comunidad política» propone esta descrip- 
ción del hombre natural rousseauniano. Para Peña este hombre natural «no es un individuo independiente, sólo existe en cuanto miembro de la comunidad a la que pertenece, la comunidad de la Naturaleza, en cuyo seno materno transcurre armónicamente su existencia. El precio que paga por estar a resguardo de los males de la civilización es la carencia de subjetividad», «Rousseau y la idea de comunidad política», Isegoría, Madrid, 11, 1995, 126-143; p. 129. Ahora bien, ies posible una comunidad sin sujetos auténticos? ¿Puede hablarse de comunidad cuando las partes que lo integran ni se saben partes y mucho menos se pueden creer miembros? Creo que hay un modo de responder afirmativamente a esta pregunta, y que consistiría en hacer depender el concepto de comunidad de algo ajeno a los hombres y que tenga, sin embargo, su consecuencia sobre ellos. Ese algo es para mí el orden de la naturaleza, orden que involucra a todas las especies por igual y del que Rousseau estaba muy seguro.

${ }^{14}$ J.-J. Rousseau, «Discurso sobre el origen...», p. 180 .

${ }^{15}$ Ibidem, pp. 183-184.

16 Ibidem, p. 153.

${ }^{17}$ Ibidem, p. 187.
${ }^{18}$ Ibidem, p. 187

19 J.-J. Rousseau, «Carta al marqués de Mirabeau», p. 156.

${ }^{20}$ J.-J. Rousseau, El contrato social, p. 436

${ }^{21}$ Ibidem, p. 401.

22 Ibidem, p. 425

${ }_{23}$ Ibidem, p. 446.

${ }^{24}$ Ibidem, p. 425.

25 Ibidem, p. 426

${ }^{26}$ Ibidem, p. 424

27 J.-J. Rousseau, Proyecto de Constitución para Córcega, p. 19.

${ }_{28}$ J.-J. Rousseau, «Consideraciones sobre...», p. 54.

${ }^{29}$ Ibidem, p. 54.

${ }^{30}$ Ibidem, p. 56.

${ }^{31}$ Ibidem, p. 71.

32 J.-J. Rousseau, «Carta a Malesherbes», en Escritos polémicos, Madrid, Tecnos, 1994, p. 42.

33 J.-J. Rousseau, «Discurso sobre el origen...», p. 184.

${ }^{34}$ Fragmento de los Premiers chefs d'oeuvres politiques de J.-J. Rousseau, citado por Alicia Villar en Cartas a Sofía, Madrid, Alianza Editorial, 1999, p. 23.

${ }^{35}$ J.-J. Rousseau, Emilio..., p. 207. 